DOI: https://doi.org/10.47405/mjssh.v6i2.677

\begin{tabular}{|c|c|}
\hline 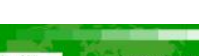 & Malaysian Journal of Social Sciences and Humanities (MJSSH) \\
\hline Malaysian Journal of & Volume 6, Issue 2, February 2021 \\
\hline (Mulassit) & e-ISSN : 2504-8562 \\
\hline & $\begin{array}{l}\text { Journal home page: } \\
\text { www.msocialsciences.com }\end{array}$ \\
\hline
\end{tabular}

\title{
Kepimpinan Transformasional Penolong Kanan Kokurikulum dan Hubungannya dengan Efikasi Guru
}

\author{
Nurul Husna Ibrahim1 ${ }^{1}$ Jamalullail Abdul Wahab ${ }^{1}$ \\ ${ }^{1}$ Fakulti Pendidikan Universiti Kebangsaan Malaysia (UKM) \\ Correspondence: Nurul Husna Ibrahim (nurhusnaibrahim@gmail.com)
}

\begin{abstract}
Abstrak
Guru Penolong Kanan Kokurikulum (GPKKo) merupakan individu yang bertanggungjawab dalam mengurus dan memimpin serta berkait langsung dengan pelaksanaan dan kegiatan kokurikulum. Justeru, GPKKo perlu mempengaruhi dan meningkatkan potensi dan efikasi guru dalam melaksanakan aktiviti kokurikulum. Artikel ini bertujuan meninjau amalan kepimpinan transformasional GPKKo dan hubungannya dengan efikasi guru dalam melaksanakan aktiviti kokurikulum di sekolah menengah daerah Sabak Bernam. Kajian ini berbentuk kuantitatif deskriptif dan inferensi dengan menggunakan instrumen soal selidik yang telah diuji kesahan dan kebolehpercayaannya dan menggunakan perisian Statistical Package for the Social Sciences (SPSS) versi 20.0. Artikel ini akan membincangkan empat dimensi kepimpinan transformasional GPKKO yang berfokus kepada memupuk pengaruh yang ideal, motivasi berinspirasi, membina ransangan intelek, serta pertimbangan berasaskan individu dan tiga dimensi efikasi guru iaitu strategi pengajaran, pengurusan bilik darjah dan penglibatan pelajar berdasarkan 140 responden yang terdiri daripada guru-guru di lima buah sekolah menengah yang terpilih di daerah Sabak Bernam. Dapatan kajian mendapati amalan kepimpinan transformasional GPKKo di daerah Sabak Bernam adalah pada tahap yang tinggi $(\min =3.8878, \mathrm{sp}=.61967)$. Kajian juga mendapati bahawa guru-guru di daerah Sabak Bernam mempunyai tahap efikasi yang tinggi $(\min =4.0740, \mathrm{sp}=.47861)$ dalam melaksanakan aktiviti kokurikulum. Hasil dapatan ujian Korelasi Pearson pula menunjukkan terdapat hubungan yang sederhana, signifikan dan positif $(r=0.473, p<0.01)$ antara amalan Kepimpinan Transformasional GPKKO dan efikasi guru. Implikasi hasil daripada dapatan ini menjadi panduan kepada GPKKo dalam menambah baik amalan kepimpinan agar tahap efikasi guru dalam melaksanakan aktiviti kokurikulum dapat dipertingkatkan. Kesimpulannya, amalan kepimpinan GPKKo mempengaruhi tahap efikasi guru dan keduanya saling berhubungan dalam pelaksanaan aktiviti kokurikulum di sekolah.
\end{abstract}

Kata kunci: kepimpinan transformasional, efikasi guru, guru penolong kanan kokurikulum

\section{Transformational Leadership of Co-curricular Senior Assistant and Its Relation with Teachers' Efficacy}

\begin{abstract}
The Co-curriculum Senior Assistant is the person who is responsible in managing and leading the implementations of co-curricular activities and its progress in schools. Therefore, the Co-curriculum Senior Assistant needs to influence and increase the potential and effectiveness of teachers in implementing co-curricular activities. This article aims to examine the transformational leadership practices of the Co-curriculum Senior Assistant and its relationship with the effectiveness of teachers in
\end{abstract}


implementing co-curricular activities in secondary schools in Sabak bernam district. This study is in the form of descriptive and inferential quantitative by using a questionnaire instrument that has been tested for validity and reliability and using Statistical Package for the Social Sciences (SPSS) 20.0 version. This article will discuss the four dimensions of the transformational leadership which focuses on cultivating ideal influence, inspiring motivation, building intellectual stimuli, as well as individualbased considerations and three dimensions of teachers' efficacy which are teaching strategies, classroom management and student engagement based on 140 respondents consisting of teachers in five selected secondary schools in Sabak Bernam district. The findings of the study found that transformational leadership practice of The Co-curriculum Senior Assistant in Sabak Bernam district are at a high level (mean=3.8878, sd=.61967). The study also found that teachers in Sabak bernam district have a high level of effectiveness (mean=4.0740, $\mathrm{sd}=.47861$ ) in implementing co-curricular activities. The results of Pearson Correlation test showed that there was a moderate, significant and positive relationship $(\mathrm{r}=0.473, \mathrm{p}<0.01)$ between transformational leadership practice of The Cocurriculum Senior Assistant and teacher's effectiveness. The implications of these findings serve as a guide for The Co-curriculum Senior Assistant in improving leadership practices so that the level of teacher effectiveness in implementing co-curricular activities can be improved too. In conclusions, transformational leadership practice of Co-curriculum Senior Assistant affects the level of teacher effectiveness and the two are interrelated in the implementation of co-curricular activities in school.

Keywords: transformational leadership, teachers' efficacy, the co-curriculum senior assistant

\section{Pengenalan}

Dalam era globalisasi yang sentiasa bergerak pantas dan ke hadapan, individu dan organisasi dituntut untuk sentiasa mempersiapkan diri untuk menghadapi cabaran dan halangan yang mendatang. Individu dan organisasi perlu sentiasa bergerak mengikut peredaran zaman supaya tidak ketinggalan dengan arus pemodenan dan globalisasi. Dalam bidang pendidikan, perubahan dan penambahbaikan tidak dapat dielak dan tetap akan berlaku sama ada dengan persetujuan ataupun tanpa persetujuan. Kegagalan melakukan atau bertindak terhadap perubahan akan menyebabkan organisasi tidak maju dan seterusnya akan gagal (Ayu, 2016). Perubahan perlu dilakukan sebagai proses penambahbaikan bagi individu mahupun organisasi. Perubahan membolehkan individu atau organisasi untuk terus cemerlang dan membangun. Justeru, pemimpin memainkan peranan penting dalam menentukan kejayaan sesebuah organisasi dan orang bawahannya.

Kepimpinan merupakan salah satu faktor yang signifikan dalam sesuatu, unit, institusi atau organisasi. Pengurusan dan perjalanan mana-mana unit, institusi atau organisasi dipengaruhi oleh pemimpinnya. Jeong, Lim \& Park (2016) mendefinisikan kepimpinan sebagai kepimpinan individu yang mempengaruhi dan membawa perubahan positif yang ketara di firma, organisasi, dan komuniti dengan memudahkan tahap kepercayaan yang sesuai, struktur dan proses organisasi dan melibatkan pelbagai pihak berkepentingan, sumber, budaya dalam pelbagai keadaan serta geografi. Dalam sesebuah unit, institusi atau organisasi, hala tuju, pengurusan dan pencapaian unit, institusi atau organisasi kebiasaannya berkait rapat dengan gaya kepimpinan yang diamalkan oleh ketua di organisasi tersebut. Menurut Lussier (2007), kepimpinan adalah kaedah mempengaruhi antara pemimpin dan pengikut untuk mencapai objektif organisasi melalui perubahan-perubahan yang mereka lakukan. Pemimpin perlu bijak mempengaruhi pengikutnya dengan perkara-perkara yang mampu membawa ke arah kejayaan organisasi.

Di sekolah, pengetua atau guru besar serta pentadbir merupakan orang yang bertanggungjawab dalam menentukan kejayaan sesebuah sekolah. Don (2007) berpendapat konsep kepimpinan sekolah boleh didefinisikan sebagai keupayaan mempengaruhi, memotivasikan, mengubah sikap dan tingkah laku subordinat supaya bersetuju melaksanakan program-program dan melakukan perubahan bagi mencapai matlamat sekolah. Pemimpin perlu mempunyai kelebihan dan keupayaan dalam mengendalikan pelbagai ragam pengikutnya dan mempunyai kemampuan untuk mempengaruhi pengikutnya agar melaksanakan seperti apa yang dikehendakinya bagi mencapai matlamat sekolah. Menurut Lee \& 
Louis (2019), bagi mewujudkan dan membentuk budaya sekolah yang kukuh dalam institusi pendidikan, pentadbir sekolah harus meningkatkan komitmen pekerja terhadap institusi tersebut untuk memenuhi harapan individu dan mewujudkan budaya sekolah yang positif. Justeru, gaya kepimpinan yang dibawa oleh pentadbir sesebuah sekolah merupakan kayu pengukur keberhasilan dan kemenjadian sesebuah sekolah.

Gaya kepimpinan yang ingin difokuskan di sini ialah gaya kepimpinan transformasi. Gaya kepimpinan transformasional merupakan antara ciri kepimpinan yang sering menjadi pilihan pemimpin. Gaya kepimpinan ini mampu menggalakkan guru-guru untuk bersedia untuk berubah dan menerima perubahan supaya mereka akan lebih komited terhadap misi dan visi pendidikan. Kepimpinan Transformasional juga dianggap antara ciri kepimpinan yang sering diamalkan kerana menurut Griffith (2004), guru yang seronok dan berpuas hati dalam kerja menyumbang kepada hasil kerja yang tinggi. Apabila guru berpuas hati terhadap kerja yang dilakukan, mereka mudah untuk menerima perubahan dengan positif dan seterusnya akan memberi peningkatan terhadap prestasi guru dan sekolah. Ini menunjukkan guru berpuas hati terhadap kerja yang dilakukan disebabkan kepimpinan yang diamalkan oleh pemimpin yang memenuhi kehendak dan harapan pengikut.

Apabila melibatkan urusan pentadbiran di sekolah, Guru Penolong Kanan Kokurikulum (GPKKo) berperanan dalam menyediakan kegiatan kokurikulum sekolah, membuat perancangan berserta takwim serta menyusun jadual latihan bagi aktiviti-aktiviti yang berkaitan dengan kokurikulum. GPKKo juga bertanggungjawab dalam meningkatkan penglibatan dan penyertaan murid dalam aktiviti kokurikulum. Peranan yang besar oleh GPKKo ini turut menyumbang dalam pembentukan modal insan iaitu melahirkan masyarakat yang berilmu dan berkemahiran tinggi dan mampu meningkatkan pembangunan negara. GPKKo berperanan sebagai pengurus dalam aktiviti kokurikulum dimana perlu membuat perancangan terbaik dan membawa perubahan kepada sekolah demi kecemerlangan dan kejayaan kokurikulum sekolah. Impak dan hasil yang positif daripada kegiatan kokurikulum di sekolah adalah hasil daripada peranan GPKKo yang memainkan tanggungjawab yang penting terhadap kokurikulum. Justeru, sangat perlu bagi GPKKo untuk menyelami bidang tugas yang dipertanggungjawabkan yang berhubung kait dengan skop tugasnya dan tidak bergantung harap melainkan daengan pimpinan pengetua dan sokongan daripada jawatankuasa kokurikulum untuk menjalankan tugas hakikinya (Zainal et al., 2016).

Efikasi guru merupakan antara faktor penting yang akan menentukan prestasi seseorang guru itu. Setiap guru mempunyai matlamat dan wawasan yang tersendiri yang telah ditetapkan bagi dirinya untuk mencapai sesuatu. Menurut Bandura (1993), beliau menerangkan bahawa efikasi kendiri adalah keyakinan seseorang terhadap kebolehannya untuk menyelaras dan menjalankan langkah-langkah yang diperlukan sepadan dengan kebolehan dan bakat yang diperoleh untuk mendapatkan keputusan yang diingini. Setiap individu perlu tahu bakat dan kemahiran yang ada pada dirinya dan mengetahui apa yang perlu dilakukan dengan kemahiran yang diperoleh bagi mencapai tujuan dan mendapatkan hasil yang diinginkan. Khalid (2012) berpendapat individu yang berada pada aras efikasi kendiri yang tinggi berupaya untuk merancang dan mencapai matlamat tugasan serta menjadikan kejayaan sebagai matlamat yang hendak dicapai. Efikasi yang tinggi memotivasikan seseorang untuk lebih berdisiplin dalam mengurus dan memantapkan matlamat yang ingin dicapai. Manakala individu yang mempunyai tahap efikasi yang rendah akan berfikiran negatif serta mempunyai motivasi yang rendah dan mengakibatkan kegagalan dalam merancang dan mencapai matlamat.

Justeru, bagi memastikan aktiviti kokurikulum berjalan dengan lancar, GPKKo perlu memainkan peranan sebagai pemimpin dalam mempengaruhi tingkah laku dan persekitaran orang bawahannya agar terus komited dan berusaha untuk menjalankan tugas dan tanggungjawabnya dalam pelaksanaan aktiviti kokurikulum. GPKKo perlu memupuk semangat dan memotivasikan guru agar efikasi mereka sentiasa berada pada aras yang tinggi seterusnya dapat melaksanakan aktiviti kokurikulum yang mana turut menyumbang kepada kecemerlangan sekolah dan pelajar. Kerajaan telah menetapkan kewajipan dalam melaksanakan aktiviti kokurikulum dan melibatkan kesemua pelajar sama ada di sekolah kerajaan mahu pun swasta (Laporan Kabinet, 1979; Akta Pendidikan, 1996). Perkara ini membuktikan kokurikulum mempunyai kepentingan yang sama seperti kurikulum di mana peranannya turut menyumbang ke arah kemajuan Pendidikan. 
Menurut Mohd Mohd Fazli et al. (2013), dalam kajiannya beliau berpendapat kegiatan kokurikulum merupakan antara proses pengajaran dan pembelajaran di luar kelas di mana akan melengkapkan lagi proses pelajaran yang telah diperoleh di dalam kelas. Penglibatan diluar kelas dapat mempamerkan transformasi sikap serta saling berkait sahsiah dan emosi pelajar. Proses pembelajaran bukan sahaja berlaku di dalam kelas, malahan diluar kelas seperti menyertai aktiviti kokurikulum, dimana pelajar dapat mempamerkan bakat yang mereka ada sama ada melalui aktiviti yang melibatkan sukan mahu pun ko-akademik. Aktiviti kokurikulum ini dapat membantu pelajar mempertingkatkan diri dengan kemahiran-kemahiran yang tidak terdapat di dalam kelas. Pengalaman yang diperoleh daripada aktiviti kokurikulum dapat dilihat hasilnya melalui kemahiran dan juga sikap pelajar seterusnya mempertingkatkan pencapaian kokurikulum pelajar. Sehubungan itu, kajian ini ingin mengenal pasti apakah tahap amalan kepimpinan transformasi guru penolong kanan kokurikulum dan hubungannya dengan efikasi guru dalam melaksanakan aktiviti kokurikulum.

\section{Sorotan Literatur}

Tanggungjawab pentadbir amat besar dalam menerajui sekolah ke arah mencapai kecemerlangan. Dalam menentukan kejayaan sesebuah sekolah, terdapat 3 aspek utama yang perlu dilihat iaitu akademik, kokurikulum dan sahsiah murid. Menurut Noor dan Suria (2016), gerak kerja kokurikulum mempunyai peranan dalam pembentukan perkembangan rohani, emosi dan jasmani pelajar. Pembentukan ini sangat diperlukan oleh sekolah bagi melahirkan pelajar berdaya saing dan berkemampuan dari pelbagai segi dan bidang. Wong (2007) berpendapat kokurikulum di sekolah seharusnya tidak dipandang enteng dan harus diutamakan oleh pentadbiran dan pengurusan di sekolah kerana mampu mempengaruhi dan membentuk kecemerlangan sahsiah dan jati diri terutama dalam kepimpinan. Namun, kebanyakan pengurusan di sekolah kurang menitikberatkan aktiviti kokurikulum sebaliknya hanya tertumpu pada akademik sahaja. Apabila terlalu fokus pada akademik, kokurikulum pelajar akan terabai seterusnya akan menyebabkan pelajar kurang berminat untuk menyertai aktiviti kokurikulum. Ini akan memberi kesan pada pentaksiran aktiviti jasmani, sukan dan kokurikulum (PAJSK) pelajar di mana markah yang akan diperoleh rendah dan tidak memuaskan.

Selain itu, pengetua dan barisan pentadbir memainkan peranan penting dalam pelaksanaan aktiviti kokurikulum. Pengetua dan pentadbir sekolah sering kali tertumpu pada kecemerlangan kurikulum berbanding kecemerlangan kokurikulum (Mohd Anuar \& Nor Azah, 2011). Kokurikulum merupakan elemen yang selalu dipandang ringan dari segi pelaksanaannya dan juga pengurusannya. Pengetua juga kurang memainkan peranannya dalam pengurusan dan perancangan aktiviti kokurikulum. Pentadbir sekolah kini berbelah bahagi dalam menumpukan kecemerlangan sama ada pada kurikulum mahu pun kokurikulum. Banyak usaha telah dilakukan yang lebih menjurus kearah kecemerlangan akademik sahaja berbanding kokurikulum pelajar-pelajar di sekolah (Zainal et al., 2016). Terdapat juga pengetua dan guru besar yang tidak mengambil peduli hal berkaitan kokurikulum. Mereka hanya menyerahkan tugasan sepenuhnya kepada GPKKo dan tidak berasa berperanan dalam hal-hal yang berkaitan kokurikulum. Jamalullail dan Azhar (2008) mendapati bahawa pengetua atau pentadbir tidak mengiktiraf dan menghargai sumbangan Guru Penolong Kanan Kokurikulum dan guru dalam melaksanakan aktiviti kokurikulum. Pengetua lebih menyasarkan untuk mencapai kecemerlangan akademik dan mengetepikan kokurikulum sehingga mengabaikan sumbangan GPKKo dan guru-guru dalam melaksanakan dan menjayakan aktiviti kokurikulum.

Kokurikulum merupakan aspek yang selalu diketepikan dan dipandang remeh dari segi pelaksanaannya dan juga pengurusannya. Sering kali pengurusan kokurikulum mengalami kekurangan sumber sama ada dari segi kewangan mahupun peralatan. Kekurangan ini akan membantutkan lagi usaha dalam meningkatkan pencapaian kokurikulum sekolah dan juga terhadap pelajar. Hal ini kerana, pengetua sekolah lebih mementingkan prestasi akademik pelajar dan hanya berfokuskan kecemerlangan sekolah dari segi kurikulum. Fenomena ini berlaku kerana pihak pentadbiran sekolah terikat dengan misi dan visi pihak berkepentingan dalam pendidikan (Zainal et al., 2016). Pengetua lebih tertumpu dalam meletakkan sekolahnya untuk tersenarai antara sekolah cemerlang dan terbaik terutama di dalam pentaksiran dan peperiksaan awam Malaysia. Justeru, perbelanjaan banyak 
diperuntukkan kepada aktiviti kurikulum, sehingga menimbulkan masalah dan kekangan kepada kelancaran aktiviti kokurikulum yang akan dijalankan (Norziana, 2013).

Menerusi kokurikulum, efikasi guru dapat dilihat apabila guru dapat melaksanakan aktiviti kokurikulum dengan baik dan penglibatan murid yang tinggi pada setiap aktiviti kokurikulum yang dijalankan. Namun terdapat segelintir guru yang tidak mahu terlibat di dalam aktiviti kokurikulum yang dijalankan. Dapatan kajian Azwan (2015) menunjukkan bahawa guru menganggap aktiviti kokurikulum sebagai suatu tugasan yang membebankan. Malah, persepsi guru akan cepat berubah apabila beban tugas semakin bertambah. Terdapat juga segelintir guru yang masih tidak mahir dalam mengendalikan dan menjalankan aktiviti kokurikulum disebabkan kurang penekanan yang diberikan kepada mereka. Jika dilihat kepada pembangunan guru, program dan latihan lebih banyak berfokus kepada pengajaran dan pembelajaran berbanding dengan kursus yang melibatkan aktiviti kokurikulum seperti kejurulatihan, perancangan aktiviti, pengendalian aktiviti kokurikulum dan sebagainya. Hal ini secara tidak langsung membantutkan usaha untuk meningkatkan pengurusan kokurikulum sekolah (Mohd Izham \& Norziana, 2015). Penekanan kepada kurikulum dan kokurikulum seharusnya seimbang kerana keduanya berperanan dalam memperkembangkan potensi pelajar daripada pelbagai aspek yang turut merangkumi aspek jasmani, emosi, rohani dan juga intelektual.

Disini, peranan pemimpin diperlukan dalam memastikan aktiviti kokurikulum ini dapat dijalankan dan dilaksanakan oleh guru-guru. Kecekapan dan kelancaran dalam menguruskan kokurikulum berkait rapat dengan kebolehan dan kebijaksanaan pemimpin di sekolah, iaitu para pentadbir. Peranan yang dimainkan oleh pengetua dan Guru Penolong Kanan Kokurikulum (GPKK) amat mempengaruhi dan membantu para guru dan pelajar melibatkan diri secara aktif dalam aktiviti kokurikulum di sekolah (Mohd Izham \& Norziana, 2015). Hal ini kerana GPKKo berkait langsung dengan pelaksanaan dan kegiatan kokurikulum dan GPKKo sebagai wakil pengetua dan pengurusan sekolah yang akan memimpin pelaksanaan kegiatan kokurikulum. GPKKo perlu mempengaruhi dan membangunkan potensi guru dan membantu guru mencapai tahap tertinggi efikasi guru dalam melaksanakan aktiviti kokurikulum. Tiffany (2017) juga berpendapat organisasi iaitu sekolah dapat membantu guru untuk mengembalikan efikasi mereka dengan melibatkan atau memandu guru dengan melihat semula jangkaan dan amalan ketika di dalam kelas, membuat penyesuaian dan mengambil perhatian dengan teliti bagi penambahbaikan dalam pembelajaran pelajar.

Selain itu, guru juga perlu mempunyai rasa tanggungjawab dan kesedaran sendiri serta berusaha bersungguh-sungguh untuk meningkatkan efikasi diri agar sentiasa bersemangat dan sentiasa positif dalam menjalankan amanah dan tanggungjawab. Peranan guru dalam melaksanakan aktiviti kokurikulum perlu ditingkatkan melalui kompetensi guru dari aspek pengetahuan, kemahiran dan sikap agar hasrat kerajaan untuk melahirkan murid yang seimbang pencapaiannya dapat direalisasikan (Haslinda, Siti Noriam \& Mohd Radzani, 2017). Justeru, guru-guru perlu mempertingkatkan kemahiran dan pemahaman dalam sesuatu ilmu serta mempersiapkan diri dengan kebolehan yang dapat membantu mereka untuk menjalankan tanggungjawab dalam tugasan berkaitan kokurikulum dan kurikulum.

\section{Kepimpinan Transformasional}

Dapatan kajian lepas oleh Hussein (2005), mendapati pencapaian sesebuah sekolah bergantung kepada gaya kepimpinan yang diamalkan dalam sekolah tersebut. Sekiranya sesebuah sekolah tersebut mengamalkan gaya kepimpinan yang positif dan cemerlang, maka akan cemerlang dan dan berkualiti lah pencapaian sekolah tersebut, begitu juga sebaliknya. Menurut Kelleher (2016), secara khususnya, pemikiran, persepsi dan tindakan pemimpin sekolah mempunyai pengaruh terhadap kejayaan sekolah dan iklim budaya. Dalam mewujudkan sekolah yang berprestasi tinggi dan cemerlang, pasti ada cabaran dan halangan dalam merealisasikan misi tersebut. Begitu juga dengan kepimpinan transformasional yang diamalkan oleh pemimpin terutamanya di sekolah berprestasi tinggi. Akan wujudnya jurang dan cabaran bagi pemimpin yang mengamalkan gaya kepimpinan ini.

Terdapat beberapa cabaran yang dihadapi oleh pemimpin dalam kepimpinan transformasional. Antaranya bagaimana tahap pemikiran seseorang mempengaruhi keengganan untuk menerima sesuatu 
perkara atau perubahan. Menurut Alsaeedi \& Male (2013), kebanyakan guru-guru yang telah bekerja di dalam bidang perguruan melebihi 25 tahun, menganggap cara kerja mereka yang tradisional itu adalah lebih baik daripada yang masih baru. Mereka agak sukar menerima perubahan dan sudah berasa di zon selesa di mana mereka merasakan perubahan yang dibawa oleh pengetua dan pentadbir yang mempunyai gaya kepimpinan transformasional ini menyusahkan dan membebankan. Menurut $\mathrm{M}$. Moradi \& Shahbazi (2016), kepimpinan transformasional dicapai apabila pemimpin dan pengikut saling memotivasikan antara satu sama lain untuk meningkatkan lagi motivasi dan moral. Saling kebergantungan antara pemimpin dan pengikut akan mencipta nilai yang lebih kepada organisasi. Abdullah \& Ainon (2006) berpendapat, pemimpin yang mengamalkan gaya kepimpinan transformasional percaya bahawa mereka boleh mendorong orang mengubah nilai dan sikap mereka supaya mereka mempunyai komitmen terhadap matlamat organisasi dan perjuangan. Oleh yang demikian, langkah untuk mengubah pemikiran mereka untuk menerima pembaharuan yang positif merupakan satu cabaran yang besar yang perlu dihadapi oleh pemimpin. Mereka tidak mahu mengikuti arus pemodenan sama ada dari segi pembelajaran, pengurusan dan pentadbiran. Malahan menolak sebarang perubahan yang berlaku di dalam pengurusan dan juga pembelajaran.

Jackson (2000), menyatakan kepimpinan transformasional memerlukan sikap toleransi yang tinggi dan sentiasa siap sedia menghadapi kekacauan dalam sesuatu proses perubahan itu. Halangan dan kekacauan dalam sesuatu proses perubahan itu pasti akan berlaku kerana terlalu banyak suara-suara yang perlu didengari (pentadbir, guru-guru, ibu bapa, staff dan pelajar-pelajar) yang akan menangguhkan proses perubahan itu dari dilaksanakan. Ini merupakan satu cabaran juga bagi pemimpin kepimpinan transformasional. Sekiranya terlalu banyak suara, kemungkinan akan berlakunya percanggahan dan perselisihan pendapat namun inilah proses yang perlu dihadapi oleh pengetua berkepimpinan transformasional bagi mendapatkan keputusan dan idea yang terbaik demi kepentingan sekolah. Apabila kepimpinan sama dikongsi di antara pentadbir dan guru terutamanya melalui amalan kepimpinan transformasional, maka hubungan kerja guru menjadi lebih kuat dan menghasilkan murid dengan pencapaian yang lebih tinggi ( Aniza, 2015). Tolak ansur dan kerjasama perlu ada di antara guru dan pentadbir untuk menjayakan aktiviti dan perkara yang telah dirancang. Menurut Zaidatol (2003), penglibatan keseluruhan seperti emosi, intelek dan moral antara pemimpin dan pengikut akan menggalakkan pengikut membentuk keupayaan melebihi kadar biasa. Di sini, pentadbir perlu bertoleransi dan bekerjasama bersama warga sekolah dalam melaksanakan segala aktiviti agar objektif sekolah tercapai. Pemimpin yang cemerlang tidak sahaja memastikan amalan pengurusan dan pentadbiran dijalankan dengan sempurna tetapi juga sentiasa mengambil berat tentang proses instruksional (Jamilah, 2015).

\section{Efikasi Guru}

Dapatan kajian lepas oleh Noornajihan \& Ab. Halim (2013), mendapati efikasi guru merupakan antara komponen utama dalam proses pengajaran dan pembelajaran yang mana ia mempengaruhi kualiti seorang guru dan amalan pengajarannya. Seseorang guru diukur berdasarkan tahap efikasi yang diperolehinya. Keupayaan guru dalam memperlihatkan potensi diri dan memotivasikan pelajar dilihat sebagai mempunyai tahap efikasi yang tinggi. Siti Awanis et al. (2016) juga berpendapat guru merupakan faktor penting dalam menentukan kejayaan pelajar dan kecemerlangan sekolah. Guru yang kompeten, fleksibel, bermotivasi tinggi dan efektif dapat mendorong dan menghasilkan pelajar yang terbaik dan cemerlang. Sebaliknya berlaku jika guru tersebut, culas, tidak bersungguh-sungguh, sering memberi alasan dan tidak bertanggungjawab dalam menjalankan tugas dan amanah yang diberikan akan memberi pengaruh buruk kepada pelajar.

Hasil dapatan kajian lampau juga turut melaporkan bahawa guru sering hilang keyakinan diri atau efikasi kendiri dan hilang tumpuan dalam proses pengajaran dan pembelajaran sekaligus menyebabkan kompetensi pengajaran lemah (Bity et al., 2007). Apabila fokus dan objektif guru tersebut hilang, ianya akan mengganggu proses pengajaran dan pembelajaran. Manakala dalam kajian Kasalak dan Dagyar (2020) mengenai hubungan efikasi guru dan kepuasan kerja guru dalam analisis berkaitan pengajaran dan pembelajaran antarabangsa, kajian mereka mendapati guru yang melihat diri mereka sebagai seorang yang kompeten dan cekap dalam kerjaya mereka akan mempunyai keyakinan efikasi yang tinggi dan kepercayaan ini mencerminkan kepuasan kerja mereka secara positif. Apabila 
kepuasan guru tercapai, efikasi kerja guru akan meningkat dan matlamat akan tercapai. Jelas sekali peranan dan tingkah laku guru berhubung kait dan berimplikasi kepada pelajar. Justeru, guru perlu sentiasa perlu positif dan mengamalkan amalan yang baik agar dapat memberi contoh kepada pelajar dan merangsang kepada kecemerlangan pelajar.

Menurut Jeff \& Sharon (2011), dalam kajiannya yang lalu, salah satu peranan pengetua, iaitu sebagai penyelia kepada guru-guru adalah dengan bekerjasama dengan guru untuk meningkatkan efikasi kendiri. Pengetua perlu menangani masalah berkaitan dengan efikasi guru dan bersama-sama bersatu dalam membentuk dan mengembangkan segala kemahiran bagi membantu dalam pencapaian murid. Bagi guru-guru baru, cabaran sebagai guru baru akan dihadapi apabila memasuki bidang keguruan ini. Pengetua dan pentadbir perlu memainkan peranan kepada guru baru dengan memberi tunjuk ajar dan panduan serta dorongan kepada mereka. Seperti yang disebutkan dalam kajian Christina Bebas (2016) dalam kajiannya, guru baru akan menghadapi rintangan dan cabaran semasa memasuki profesion keguruan untuk beberapa tahun yang pertama. oleh yang demikian, keupayaan mereka untuk bertahan sangat dipengaruhi oleh tahap efikasi mereka. Justeru, pengetua perlu memberi dorongan dan bantuan kepada guru baru untuk mempertingkatkan efikasi kerana guru baru mempunyai pengaruh yang besar terhadap pelajar.

\section{Metod Kajian}

Kajian ini adalah kajian tinjauan berbentuk deskriptif. Menurut Sabitha (2005) kaedah tinjauan lebih sesuai digunakan untuk mendapatkan maklumat yang melibatkan keseluruhan populasi. Instrumen soal selidik dalam bentuk 'google form' digunakan untuk mengumpul data dalam kajian ini. Instrumen soal selidik yang digunakan adalah adaptasi daripada Hallinger dan Murphy (1987) Principal Instructional Management Rating Scale (PIMRS) untuk mengukur tahap kepimpinan transformasional Guru Penolong Kanan Kokurikulum.

Analisis kajian menggunakan statistik deskriptif melalui perisian SPSS versi 23 bagi menjawab persoalan kajian. Soal selidik yang digunakan dalam kaedah ini adalah soal selidik yang dibina menggunakan skala nisbah (skala Likert) iaitu, 1= Sangat Tidak Setuju (STS), 2= Tidak Setuju (TS), 3= Tidak Pasti (TP), 4= Setuju (S) dan 5= Sangat Setuju (SS). Manakala, borang soal selidik dibahagikan kepada tiga bahagian iaitu bahagian A mengukur maklumat mengenai peribadi guru, bahagian B pula mengukur Amalan Kepemimpinan Transformasional Guru Penolong Kanan Kokurikulum dan bahagian C pula mengukur Efikasi Guru Dalam Melaksanakan Aktiviti Kokurikulum. Sampel kajian ini adalah terdiri daripada 140 orang guru-guru di 5 buah sekolah menengah yang terpilih daerah Sabak Bernam.

\section{Hasil Kajian}

Analisis dapatan kajian berdasarkan tiga bahagian dalam instrumen iaitu bahagian A (demografi responden), bahagian B (Tahap Kepimpinan Transformasional GPKKo) dan bahagian C (Tahap Efikasi Guru). Kajian ini telah melibatkan 140 orang guru dan pentadbir daripada lima buah sekolah menengah aliran agama di daerah Sabak Bernam. Berdasarkan jadual 1, kebanyakan responden adalah daripada guru perempuan iaitu sebanyak 87 responden dengan $62.1 \%$ manakala 53 responden yang lain dengan peratus $37.9 \%$ adalah daripada lelaki. Melalui jadual ini, boleh dirumuskan bahawa responden perempuan merupakan penyumbang terbesar dalam kajian ini. Bagi pengalaman mengajar pula, bilangan guru yang mempunyai pengalaman mengajar lebih 20 tahun iaitu sebanyak 52 responden dengan peratus $37.1 \%$ merupakan responden tertinggi dalam kajian ini, manakala pengalaman mengajar kurang daripada 5 tahun dengan jumlah 17 orang responden iaitu $12.1 \%$ merupakan responden yang paling kurang dalam kajian ini. 
Jadual 1: Demografi Responden Berdasarkan Jantina Dan Pengalaman Mengajar

\begin{tabular}{cccc}
\hline \multicolumn{2}{c}{ Responden } & Frekuensi & Peratus\% \\
\hline \multirow{3}{*}{ Jantina } & Lelaki & 53 & 37.9 \\
& Perempuan & 87 & 62.1 \\
\cline { 2 - 4 } & Jumlah & $\mathbf{1 4 0}$ & $\mathbf{1 0 0 . 0}$ \\
\cline { 2 - 4 } & & & \\
\multirow{3}{*}{ Pengalaman } & < 5 Tahun & 17 & 12.1 \\
Mengajar & 5-10 tahun & 28 & 20.0 \\
& 11-19 Tahun & 43 & 30.7 \\
& > 20 Tahun & 52 & 37.1 \\
\cline { 2 - 4 } & Jumlah & $\mathbf{1 4 0}$ & $\mathbf{1 0 0 . 0}$ \\
\cline { 2 - 4 } & & &
\end{tabular}

Berdasarkan jadual 2, dapatan menunjukkan min keseluruhan dimensi kepimpinan Transformasional adalah 3.8878 dengan sisihan piawai .61967. Skor min bagi ketiga-tiga pembolehubah menunjukkan tahap amalan kepimpinan transformasional GPKKo adalah tinggi. Skor min bagi pembolehubah Motivasi Berinspirasi adalah yang tertinggi $(\min =3.9257$, $\mathrm{sp}=.68754)$ diikuti Memupuk Pengaruh yang Ideal $(\mathrm{min}=3.9229, \mathrm{sp}=.76076)$ berbanding Pertimbangan Berasaskan Individu $(\mathrm{min}=3.8457$, $\mathrm{sp}=.66021)$ dan Membina Ransangan Intelek ( $\min =3.8571, \mathrm{sp}=.68836)$.

Jadual 2: Tahap Kepimpinan Transformasional GPKKo

\begin{tabular}{llll}
\hline Dimensi & Min & Sisihan Piawaian & Tahap \\
\hline Memupuk Pengaruh yang Ideal & 3.9229 & .76076 & Tinggi \\
Pertimbangan Berasaskan Individu & 3.8457 & .66021 & Tinggi \\
Membina Ransangan Intelek & 3.8571 & .68836 & Tinggi \\
Motivasi Berinspirasi & 3.9257 & .68754 & Tinggi \\
\hline Jumlah keseluruhan & 3.8878 & .61967 & Tinggi \\
\hline
\end{tabular}

Jadual 3 menunjukkan dapatan kajian bagi tahap efikasi guru-guru di sekolah menengah daerah Sabak Bernam dalam melaksanakan aktiviti kokurikulum. Secara keseluruhan, tahap efikasi guru berada pada tahap yang tinggi dengan nilai min 4.0740 dan sisihan piawai .47861. Dimensi strategi pengajaran merupakan dimensi yang tertinggi dalam tahap efikasi guru dengan nilai min $4.1439 \quad(\mathrm{sp}=.51669)$ diikuti dengan Penglibatan Pelajar ( $\mathrm{min}=4.0755, \mathrm{sp}=.60280)$ dan Pengurusan Bilik Darjah ( $\min =4.1439, \mathrm{sp}=.52636$ ).

Jadual 3: Tahap Efikasi Guru

\begin{tabular}{llll}
\hline Dimensi & Min & Sisihan Piawaian & Tahap \\
\hline Strategi Pengajaran & 4.1439 & .51669 & Tinggi \\
Pengurusan Bilik Darjah & 4.0027 & .52636 & Tinggi \\
Penglibatan Pelajar & 4.0755 & .60280 & Tinggi \\
\hline Jumlah keseluruhan & 4.0740 & .47861 & Tinggi \\
\hline
\end{tabular}

Jadual 4 menunjukkan hasil dapatan ujian korelasi Pearson iaitu terdapat hubungan yang signifikan $(\mathrm{r}=0.473, \mathrm{p}<0.01)$ antara Tahap Amalan Kepimpinan Transformasional GPKKO dan Tahap Efikasi Guru dalam melaksanakan aktiviti kokurikulum. Hasil kajian mendapati terdapat hubungan yang sederhana antara amalan Kepimpinan Transformasional GPKKO dengan efikasi guru. Ini menunjukkan GPKKO masih kurang mengamalkan Amalan Kepimpinan Transformasional. Namun terdapat hubungan yang positif berdasarkan nilai pekali Pearson $r$ yang mana telah menunjukkan sekiranya Amalan Kepimpinan Transformasional GPKKO meningkat, maka efikasi guru dalam melaksanakan aktiviti kokurikulum juga meningkat secara tidak langsung hipotesis HO1 ditolak. 
Jadual 4: Hubungan Antara Tahap Amalan Kepimpinan Transformasional GPKKO dan Tahap Efikasi Guru.

\begin{tabular}{llll}
\hline & & $\begin{array}{l}\text { Kepimpinan } \\
\text { Transformasional }\end{array}$ & Efikasi guru \\
\hline Kepimpinan Transformasional & Kolerasi Pearson & 1 & $.473^{* *}$ \\
GPKKO & Sig. (2-tailed) & & .000 \\
& $\mathrm{~N}$ & 140 & 140 \\
Efikasi guru dalam melaksanakan & Kolerasi Pearson & $.473^{* *}$ & 1 \\
aktiviti kokurikulum & Sig. (2-tailed) & .000 & \\
& $\mathrm{~N}$ & 140 & 140 \\
\hline
\end{tabular}

\section{Perbincangan Kajian}

\section{Tahap Amalan Kepimpinan Transformasional GPKKo}

Hasil kajian mendapati tahap amalan kepimpinan transformasional GPKKo Secara keseluruhannya berada pada tahap yang tinggi. Dapatan ini menunjukkan GPKKO mengamalkan gaya kepimpinan transformasional di sekolah. Dapatan ini menunjukkan guru-guru di sekolah menengah daerah Sabak Bernam bersetuju dengan kepimpinan transformasional yang diamalkan oleh GPKKO mereka. Hasil kajian ini selaras dengan kajian Ahmad Yusri (2016), yang menyatakan gaya kepimpinan transformasional lebih banyak diamalkan oleh pengetua sekolah menengah berbanding dengan kepimpinan transaksi. Kepimpinan transformasional menjadi pilihan dalam kebanyakan pengetua sekolah dan mempunyai tahap amalan yang tinggi dalam kalangan pentadbir. Kajian ini bersependapat dengan dapatan oleh Stefan et al. (2018) yang mengatakan pemboleh ubah yang penting untuk membangunkan efikasi guru adalah kepimpinan transformasional sekolah. Amalan kepimpinan transformasional berperanan dalam meningkatkan tahap efikasi guru dalam melaksanakan tanggungjawab yang telah ditugaskan.

Ini menunjukkan kepimpinan transformasional adalah peramal terbaik bagi pentadbir untuk memotivasikan guru seterusnya meningkatkan efikasi kendiri guru. Jika dilihat pada jumlah min bagi setiap konstruk, kesemuanya memiliki nilai min yang tinggi. Skor min bagi pemboleh ubah Motivasi Berinspirasi adalah yang tertinggi dalam dimensi kepimpinan transformasional $(\mathrm{min}=3.9257$, $\mathrm{sp}=.68754)$. Ini menjelaskan kebanyakan GPKKo di daerah Sabak Bernam bermotivasi tinggi dan sentiasa mempunyai matlamat yang jelas yang mana dikongsi dengan pengikutnya. GPKKo di daerah Sabak Bernam menyatakan visi yang menarik dan memberi inspirasi kepada para pengikut. Kajian Button (2003) menunjukkan bahawa guru yang berkesan adalah dalam kalangan guru yang bermotivasi tinggi.

Pemimpin dengan motivasi inspirasi sentiasa berfikir jauh ke hadapan dan sentiasa maju ke hadapan. Pemimpin seperti ini sentiasa mahukan yang terbaik untuk pengikut dan juga organisasinya. Mereka sentiasa mendorong dan menggalakkan pengikutnya untuk melihat sesuatu dengan jangka masa panjang dan mempunyai matlamat yang jelas. Motivasi guru adalah faktor penting yang mempunyai hubungan dengan beberapa pemboleh ubah dalam bidang Pendidikan seperti motivasi pelajar, amalan pengajaran, dan kepuasan kerja guru. Motivasi juga penting untuk memastikan guru kekal bertenaga dan gigih dalam pengajaran dan pembelajaran (Selcuk, 2020). Pengikut perlu mempunyai tujuan jelas dan spesifik untuk melakukan sebarang tindakan dan sentiasa termotivasi walau apa keadaan sekalipun. Apabila pengikut memahami tujuan dan matlamat yang ingin dicapai, ini akan mendorong mereka untuk terus bergerak bersama-sama pemimpin untuk mencapai matlamat dan merealisasikannya.

Selain itu, kepimpinan turut disokong oleh kemahiran komunikasi yang menjadikan objektif, misi dan visi itu jelas difahami, tepat, berkuasa dan menarik. Para pengikut bersedia untuk memajukan diri dalam setiap skop tugas mereka, dan sentiasa optimis dan realistik mengenai masa depan dan percaya kepada bakat dan kemahiran mereka. Begitu juga kajian yang dijalankan oleh Habib dan Zaimah 
(2012), Rosmawati (2013) dan Mohamad Radzi et al. (2014) juga mempunyai dapatan yang sama iaitu kepimpinan transformasi pengetua di sekolah berada pada tahap yang tinggi. Ini jelas menunjukkan kebanyakkan pemimpin sekolah mengamalkan kepimpinan transformasional. Selaras dengan pendapat Korejan \& Shahbazi (2016) dalam kajian mereka bahawa pemimpin transformasional memotivasikan pekerja mereka untuk melakukan lebih daripada apa yang sepatutnya dan bertumpu kepada keperluan guru yang mana lebih utama. Pemimpin transformasional juga bertindak sebagai pembimbing dan penasihat dan fokus kepada perkembangan pembelajaran. Mereka juga mewujudkan persaingan untuk mencapai misi, perasaan dan hormat kepada sesama guru dan berperanan sebagai contoh kepada guru yang lain.

\section{Tahap Efikasi Guru}

Secara keseluruhannya, tahap efikasi guru dalam melaksanakan aktiviti kokurikulum berada pada tahap yang tinggi. Hasil dapatan ini menunjukkan guru-guru di daerah Sabak Bernam mempunyai efikasi yang tinggi dalam melaksanakan aktiviti kokurikulum di sekolah. Dapatan ini selari dengan dapatan Syed Kamaruzaman et al. (2014) yang mendapati tahap efikasi kendiri guru adalah tinggi tanpa mengira jantina. Ketiga-tiga konstruk dalam tahap efikasi guru menunjukkan jumlah min yang tinggi iaitu mencapai 4.0. Dapatan ini turut disokong dengan dapatan dari Awanis et al. (2016) dalam membincangkan tentang hubungan tahap efikasi guru dengan pencapaian sekolah mendapati tahap efikasi guru adalah tinggi iaitu nilai min skor 4.03 bagi efikasi kendiri dan 3.73 bagi efikasi mengajar. Manakala bagi efikasi guru secara keseluruhannya menunjukkan nilai min skor adalah 3.90. Little (2020) dalam kajiannya mendapati kepercayaan mengenai efikasi diri secara berterusan mempengaruhi tingkah laku pengajaran dan kepercayaan. Peningkatan efikasi secara umumnya akakn membawa kepada peningkatan usaha dan tahap prestasi. Tahap efikasi yang tinggi dalam kalangan guru ini mampu mengubah pelajar kearah yang lebih baik dan yakin akan potensi dan kemahiran yang dimiliki oleh guru tersebut akan menghasilkan keputusan yang positif dan sentiasa berusaha untuk memperhebatkan diri demi pelajar dan mencapai matlamat organisasinya.

Dalam kajian ini, dimensi strategi pengajaran merupakan dimensi yang mempunyai min yang tertinggi dengan nilai min 4.1439, sp=.51669 dalam tahap efikasi guru. Ini menunjukkan guru-guru di daerah Sabak Bernam berpengalaman dalam mengendalikan strategi pengajaran dan pembelajaran ketika melaksanakan aktiviti kokurikulum. Strategi pengajaran merupakan kebijaksanaan memilih, merancang, dan menguruskan kaedah serta teknik pengajaran untuk menghasilkan pencapaian yang optimum. Guru-guru perlu mahir dan intelek dalam menyesuaikan strategi pengajaran terkini dengan generasi pelajar yang ada pada masa kini. Guru yang berpengalaman akan lebih mudah untuk menyusun teknik pengajaran iaitu merujuk kepada kemahiran guru mendepani dan mengatur kaedah pembelajaran. Bandura (1997) yang menyatakan efikasi kendiri guru wujud berdasarkan pengalaman dan penilaian spesifiknya terhadap tugas yang hendak dilakukan. Persepsi terhadap tugas turut mempengaruhi tahap efikasi kendiri guru.

Guru perlu lebih kreatif dan mengikuti era teknologi kerana generasi pelajar masa kini cenderung ke arah menggunakan teknologi moden. Guru yang berpengalaman merupakan antara guru yang mahir dalam mengatur strategi pengajaran. Hal ini kerana, pengalaman kerja secara tidak langsung membantu dalam meningkatkan efikasi guru. Dapatan ini sejajar dengan Emmer dan Hickman (1991) yang mengatakan efikasi guru menyumbang pengaruh yang konsisten ke atas aspek-aspek pengajaran berkesan, seperti merancang strategi pembelajaran yang berkesan. Namun, dapatan bercanggah dengan Noor Ashikin (2017) yang menyatakan apabila berhadapan dengan tugasan pengajaran yang baharu atau sukar, guru akan memfokuskan kepada rintangan tetapi tidak menumpukan usaha untuk mengatasi rintangan tersebut. Keadaan ini mewujudkan hilang keyakinan dan kurang termotivasi dalam kalangan guru dan sentiasa membuat alasan untuk mengelak daripada memegang tanggungjawab.

\section{Hubungan Antara Tahap Amalan Kepimpinan Transformasional GPKKo dan Tahap Efikasi Guru}


Hasil dapatan kajian ini membuktikan bahawa gaya kepimpinan transformasional GPKKo mempunyai hubungan yang sederhana, signifikan dan positif antara amalan Kepimpinan Transformasional GPKKO dan efikasi guru. Hasil dapatan ini adalah selaras dengan dapatan Masitah et. al. (2013) dalam kajiannya iaitu faktor-faktor yang mempengaruhi efikasi kendiri dalam pelaksanaan Pendidikan alam sekitar. Terdapat hubungan yang positif dan sederhana di antara efikasi kendiri guru dengan keempat-empat pemboleh ubah dalam kajian beliau dalam pelaksanaan Pendidikan alam sekitar. Begitu juga dengan hasil dapatan Kasalak \& Dagyar (2020) yang menunjukkan terdapat hubungan yang positif antara efikasi kendiri guru dan kepuasan kerja guru. Dapatan mereka ini menunjukkan apabila efikasi guru meningkat, kepuasan kerja guru juga meningkat. Efikasi kendiri yang tinggi mampu mengelakkan guru mengalami tekanan kerja dan kemurungan ketika melaksanakan kerja.

Bagi kajian ini pula, hubungan yang sederhana mungkin disebabkan ada faktor lain yang lebih bersesuaian dengan pemboleh ubah yang dikaji ini. Walaupun tahap kepimpinan dan efikasi tinggi, namun hubungan keduanya sederhana. Tindakan perlu diambil kerana menurut kajian oleh Stump M K (2016) telah menunjukkan tahap kepimpinan transformasional guru besar akan meningkatkan tahap efikasi guru. Ini bermaksud pemimpin perlu memainkan peranan dengan mempengaruhi bawahannya agar efikasi guru dapat ditingkatkan. Namun, terdapat juga percanggahan dalam dapatan ini dengan dapatan dari kajian oleh Kalaivani dan Azlin (2018) mendapati hubungan antara kedua-dua pemboleh ubah ini adalah positif tetapi rendah. Hubungan yang rendah akan memberikan impak negatif terhadap efikasi pentadbir dan guru perlu bersemuka dan berbincang isu atau masalah yang dihadapi agar masalah yang berlaku dalam kepimpinan dan efikasi guru dapat diatasi.

\section{Implikasi kajian}

Implikasi daripada kajian ini mendapati bahawa tahap kepimpinan transformasional GPKKo dan tahap efikasi guru dalam melaksanakan koko adalah tinggi. Ini menunjukkan dimensi kepimpinan iaitu memupuk pengaruh yang ideal, motivasi berinspirasi, membina rangsangan intelek dan pertimbangan berasaskan individu diamalkan dengan baik oleh GPKKo. Begitu juga dengan dimensi efikasi iaitu strategi pengajaran, pengurusan bilik darjah dan penglibatan pelajar juga diamalkan dengan baik oleh guru dalam melaksanakan aktiviti kokurikulum. Namun hubungan kedua-dua dimensi tersebut adalah sederhana. Hal ini menunjukkan, terdapat faktor lain yang mempengaruhi guru dalam melaksanakan aktiviti kokurikulum. Apabila hubungan yang sederhana antara kedua pemboleh ubah, akan menyebabkan arahan yang diberikan oleh GPKKo tidak disambut baik oleh guru. Ini akan mengakibatkan guru tidak dapat menjalankan tugasnya dengan baik.

Selain itu, GPKKo juga dapat menjadikan panduan dalam memimpin guru dan memainkan peranan sebagai wakil pengetua dalam menguruskan aktiviti yang melibatkan kokurikulum. GPKKo juga sebenarnya merupakan individu yang sama penting dan berperanan besar seperti pentadbir yang lain dalam memastikan perjalanan dan kelancaran aktiviti di sekolah. Dengan tanggungjawab dan kerja yang digalas oleh GPKKo, kecemerlangan pelajar dan sekolah dapat dicapai. Kajian ini juga dapat dijadikan rujukan bukan sahaja di sekolah, malahan di syarikat atau organisasi kecil mahu pun yang besar, boleh menjadi panduan dalam mentadbir dan menguruskan organisasi. Selain itu, pelaksanaan aktiviti kokurikulum juga dapat ditingkatkan. Kokurikulum memainkan peranan penting sebagai salah satu aspek yang diperlukan dalam pembangunan modal insan. Pencapaian kokurikulum dan akademik pelajar perlu selari bagi melahirkan masyarakat yang berwawasan, maju ke hadapan, berdaya saing, berilmu dan berkemahiran tinggi.

\section{Cadangan}

Antara cadangan terhadap sistem pendidikan Malaysia ialah melalui Dasar Pendidikan Guru. Dasar Pendidikan Guru merujuk kepada Dasar Pendidikan Kebangsaan (2012) di mana dasar ini memfokuskan kepada guru iaitu dengan menyediakan latihan guru bagi melengkapkan guru dengan ilmu pengetahuan, sikap, tingkah laku dan kemahiran yang diperlukan. Antara strategi dasar ini adalah untuk menyediakan guru terlatih yang berkualiti dan kompeten dalam aspek amalan nilai profesionalisme keguruan, pengetahuan dan kefahaman serta kemahiran pengajaran dan pembelajaran berdasarkan Standard Guru Malaysia (SGM). 
Seterusnya memberi latihan. Latihan perlu diberikan kepada guru-guru setiap kali ada perubahan baru yang diarahkan oleh KPM. Latihan perguruan direka bentuk berdasarkan Falsafah Pendidikan Kebangsaan dan Falsafah Pendidikan Guru untuk melahirkan guru yang profesional, berketerampilan, berdaya saing, berakhlak mulia, mengamalkan nilai-nilai murni, mahir berfikir dan cekap teknologi (Dasar Pendidikan Kebangsaan, 2012). Latihan dalam perkhidmatan (LADAP) seperti kemahiran komunikasi, kemahiran interpersonal dan sebagainya dapat meningkatkan tahap profesionalisme guru secara berterusan ke arah guru berkualiti dan kekal berkualiti. Apabila guru memiliki pelbagai kemahiran, efikasi guru dapat ditingkatkan.

Cadangan seterusnya adalah perbincangan antara pentadbir dan guru-guru. Apabila terdapat sesuatu isu atau masalah, pentadbir perlu menyampaikan maklumat dan arahan dengan jelas. Perbincangan ini untuk memastikan guru berada di landasan yang betul ketika melakukan aktiviti atau menjalankan tugas. Hal ini kerana, salah faham sering berlaku dalam kalangan guru apabila mereka tidak jelas dengan apa yang disampaikan. Justeru pentadbir perlu sentiasa memberikan contoh yang baik dan sentiasa memotivasikan guru-guru. Apabila guru-guru termotivasi, mereka akan merasai kepuasan kerja dan meningkatkan prestasi.

\section{Kesimpulan}

Kesimpulannya, amalan kepimpinan transformasional berhubungan dengan efikasi guru. Semakin tinggi amalan kepimpinan GPKKo, semakin tinggi tahap efikasi guru. Hubungan antara kepimpinan transformasional GPKKo dengan tahap efikasi guru perlu diperbaiki dan ditambah baik. Tahap efikasi guru yang tinggi memotivasikan guru untuk melaksanakan perubahan dan mempengaruhi guru-guru untuk terus semangat menjayakan apa sahaja tugasan yang diberikan.

\section{Rujukan}

Abdullah Hassan dan Ainon Mohd (2007). Teori dan Teknik Kepimpinan: Panduan Aplikasi di Tempat Kerja. Kuala Lumpur: PTS Professional Publishing Sdn. Bhd.

Ahmad Esa, Mohd. Khir Mohd Nor, Nawawi Jusoh, Norashidah Abd Rahman \& Zalinah Salehon. 2015. Citra Kokurikulum. Penerbit UTHM.

Ahmad Yusri Ismail. (2016). Gaya Kepimpinan Pengetua dan Kepuasan Kerja Guru Di Sekolah Menengah Kebangsaan Daerah Marang, Terengganu. International Seminar on Generating Knowledge Through Research, UUM-UMSIDA, 25-27 Oktober 2016.

Alsaeedi, F., \& Male, T. (2013). Transformational Leadership \& Globalization : Attitudes of School Principals in Kuwait'. Educational Management Administration and Leadership, 41 (5), 640-657.

Aniza Baharuddin. (2015). Amalan Kepimpinan Pengajaran dan Transformasional Pengetua Serta Hubungannya Dengan Ciri Sekolah Mnengah Harian Berprestasi Tinggi DI Pahang. Uiversiti Putra Malaysia.

Azwan Wamin. (2015). Hubungan Antara Sikap Guru Terhadap Kokurikulum Sekolah Berasrama Penuh di Negeri Selangor. Tesis Sarjana Pendidikan. Universiti Pendidikan Sultan Idris

Avolio, B. J. dan Bass, B.M. (1988). Transformational and Leadership, Charisma, and Beyond. Emerging Leadership Vistas. J.G. Hunt et al. (eds). Lexington, MA: Lexington Books.

Ayu Diana Awang. 2016. Pengurusan Perubahan Dalam Organisasi. Sektor Hartanah Dan Industri Pembinaan.1-8.

Alyssa N. Rockenbach, Matthew J. Mayhew, Shauna Morin, Rebecca E. Crandall, and Ben Selznick. (2015). Fostering the Pluralism Orientation of College Students through Interfaith Co-curricular Engagement. The Review of Higher Education Fall, 39(1).

A.W. Kamau, Rintaugu, R.K. Muniu \& L.O. Amusa. 2015. The Effect of Participation in Competitive Sports on School Connectedness of Secondary School Students. African Journal for Physical, Health Education, Recreation and Dance (AJPHERD), 21(3). 
Baharuddin, A., Akmaliah, Z., \& Lope, P. (2014) Amalan Kepemimpinan Pengajaran Dan Transformasi Pengetua Dan Hubungannya Dengan Prestasi Sekolah. Jurnal Pengurusan Dan Kepimpinan Pendidikan, 28(2),107-121.

Bandura, A. (1993). Perceived Self-Efficacy In Cognitif Development And Functioning. Educational Psychologist, 28(2), 117-148.

Bass, B., \& Riggio, R. (2006). Transformational Leadership [Ebook] (2nd ed., pp. 1-10). Mahwah: Lawrence Erlbaum Associates. $\quad$ Retrieved from https://www.academia.edu/34579754/Bernard_M._Bass_Ronald_E._Riggio_Transformational_L eadership_Second_Edition_Lawrence_Erlbaum_Associates_2005_

Bass, B.M. (1998). Transformational leadership: Industry, Military and Educational Impact. Mahwah.

Bity Salwana Alias et al. (2007). Kompetensi pengetua sekolah menengah Malaysia dalam bidang pengurusan kurikulum. Kertas kerja Seminar Nasional Pengurusan dan Kepimpinan Pendidikanke-15 IAB, Genting Highland.

Burns, J.M. (1978). Leadership. New York: Harper \& Row.

Button, B. (2003). A Study Examining the Use of Transformational Leadership Practices for the teacher development. https://minds. wisconsin.edu/bitstream/handle/1793/40765/2003buttonb.pdf?sequence=1\&isAllow ed=y [15 Mei 2020].

Bryk, A. S., Lee, V. E., \& Holland, P. B. (1993). Catholic schools and the common good. Cambridge, MA: Harvard University Press.

Chang \& Engelhand. (2016). Examining the Teachers' Sense of Efficacy Scale at the Item Level With Rasch Measurement Model.

Christina Bebas. (2016). School University Partnerships: The Professional Development Schools Model, Self-Efficacy, Teacher Efficacy, and Its Impact on Beginning Teachers. Worcester State University.

Donny Susilo. (2018). Transformational Leadership; A Style Of Motivating Employees. Management And Economics Journal, 2(2).

Emmer, E. T., \& Hickman, J. (1991). Teacher Efficacy In Classroom Management And Discipline. Educational And Psychological Measurement, 51, 755-765.

Griffith, J. (2004). Relation of Principal Transformational Leadership to School Staff Job Satisfaction, Staff Turnover and School Perfomance. Journal of Educational Administration, 42(3), 333-356.

Guskey, T.R. \& Passaro, P. (1994). Teacher Efficacy: A Study Of Construct Dimensions. American Educational Research Journal, 31, 627-643.

Habib Ismail \& Zaimah Ramli. (2012). Amalan Kepimpinan Transformasi Pengetua dan Hubungannya Dengan Kepuasan Kerja Guru. PROSIDING PERKEM VII. 2: 1471 - 1478. http://www.ukm.my/fep/perkem/pdf/perkemVII/PKEM2012_5C5.pdf [15 Mei 2020].

Hallinger, P. (2003). Leading Educational Change: reflections on the practice of instructional and transformational leadership. Cambridge Journal Of Education, 33(3), 329-352. doi: 10.1080/0305764032000122005

Hallinger, P., Murphy, J. 1987). Assessing and developing principal instructional leadership. Educational Leadership, 45(1), 54 -61.

Haslinda, Siti Noriam \& Mohd Radzani. (2017). Kompetensi Guru Dan Hubungannya Dengan Pencapaian Kokurikulum Murid Di Sekolah Menengah

Hishamuddin, Mohd Rizal \& Supian. 2018. Hubungan Antara Kepimpinan Transformasi Guru Besar Dengan Kepuasan Kerja Guru Di Sekolah Kebangsaan Kurang Murid Gemilang Tujuh Segamat, Johor. Universiti Teknologi Malaysia.

Hussein Mahmood. (2005). Kepemimpinan profesionalisme: Satu utopia? Pemimpin, 5, 39-51.

Isa, J. M. (2009). Gaya kepemimpinan pengetua dan kepuasan kerja guru: Kajian Perbandingan antara SMKA dengan SMK.

Ishak bin Sin. (2002). "Gaya kepimpinan yang digemari: Satu Kajian Kes-Kes Hipotetikal.” Kertas kerja yang dibentangkan dalam Seminar Pengurusan dan Kepimpinan Pendidikan kali ke-XI, pada 17-19 Disember 2002, Di Hotel Pan Pasific, Kuala Lumpur International Airport, Sepang.

Jamalullail Abdul Wahab \& Azhar Abdul Kadir. (2008). Kajian faktor-faktor keberkesanan pelaksanaan pengurusan kokurikulum daripada persepsi guru penolong kanak sekolah-sekolah 
menengah daerah Hulu Langat, Selangor. Jurnal Pengurusan dan Kepimpinan Pendidikan, 8(1), 20-36.

Jamilah Ahmad. (2015). Amalan Kepimpinan Transformasiona Pengetua Sekolah Berprestasi Tinggi Di Malaysia. Universiti Teknologi Malaysia.

Jackson, D. 2000. The School Improvement Journey: Perspectives on Leadership. School Leadership \& Management, 20(1), 61-78.

Jeff Walker \& Sharon Slear (2011). The Impact of Principal Leadership Behaviors on the Efficacy of New and Experienced Middle School Teachers.

Jeong, S., Lim, D., \& Park, S. (2016). Leadership convergence and divergence in the era of globalization. In P. O. Pablos \& R. D. Tennyson (Eds.), Handbook of research on human resources strategies for the new millennial workforce (pp. 285-308). Hershey, PA: IGI Global. doi:10.4018/978-1-5225-0948-6

Kalaivani A/P Muniandy \& Azlin Norhaini Binti Mansor. (2018). Kepimpinan Transformasional Guru Besar dan Hubungannya dengan Tahap Efikasi Kendiri Guru. 1-9. https://seminar.utmspace.edu.my/lspgabc2018/Doc/20.pdf [22 Mei 2020].

Kelleher, J. (2016). Art in Action. Educational Leadership.

Khalid Johari. (2012). Perkembangan Efikasi Guru Sekolah Menengah Di Sabah. Jurnal Kemanusiaan, 20.

Khalip Musa, Hamidah Yusof, Jamal@Nordin Yunus \& Suriani Abdul Hamid. (2014). Kepimpinan Transformasional Pengetua: Perbandingan Antara Sekolah Menengah Awam dan Swasta Cemerlang. Management Research Journal.

Kasalak \& Dagyar, (2020). The Relationship between Teacher Self-Efficacy and Teacher Job Satisfaction: A Meta-Analysis of the Teaching and Learning International Survey (TALIS). Educational Sciences: Theory \& Practice.

Laporan Jawatankuasa Kabinet. (1979). Mengkaji pelaksanaan dasar pelajaran. Kuala Lumpur: Dewan Bahasa dan Pustaka.

Laman Web Rasmi. Majlis Daerah Sabak Bernam. Pendidikan. http://www.mdsb.gov.my/ms/pelawat/pendidikan/sekolah [ 2 Jun 2020].

Lee, M., \& Louis, K. S. (2019). Mapping a strong school culture and linking it to sustainable school improvement. Teaching and Teacher Education.

Leithwood, K. dan Jantzi, D. (1996). Towards an explanation of variation in teachers' perceptions of transformational school leadership. Educational Administration Quarterly, 32(4), 512-538

Little, M. E. (2020). Collaboration and Connections among Middle School Teachers of Mathematics: Enhancing Efficacy through Professional Learning Communities. SRATE Journal. University of Central Florida.

Lussier, R.N. \& Achua C.F. (2007). Leadership : Theory, Application, Skill Development. Ohio: South-Western College.

M. Moradi Korejan \& H. Shahbazi, (2016). An Analysis Of The Transformational Leadership Theory. Journal of Fundamental and Applied Sciences.

Masitah et. al. (2013). Faktor- Faktor Yang Mempengaruhi Efikasikendiri Guru Sekolah Menengah Di Malaysia Dalam Pelaksanaan Pendidikan Alam Sekitar. Asia Pacific Journal of Educators and Education, 28, 131-153.

Mohd Anuar Abdul Rahman \& Nor Azah Azman. (2011). Peranan Pengetua Sebagai Pengurus Kokurikulum di Sekolah Menengah Daerah Mersing. Journal of Educational Management. 14 30. http://eprints.utm.my/id/eprint/12150/1/JEM-2011-1-002.pdf [12 Mei 2020].

Mohd Fazli Hassan, Suhaida Abdul Kadir, \& Soaib Asimiran. (2013). Hubungan Persekitaran Sekolah dengan Penglibatan Pelajar dalam Aktiviti Kokurikulum di Sekolah Menengah, 38(2), 1-9.

Mohd Izham Mohd Hamzah \& Norziana Ayob. (2015). Peranan Pengetua dalam Pengurusan Kokurikulum dari Perspektif Guru Sekolah Menengah Kebangsaan Zon Keramat. Jurnal Pendidikan Malaysia, 40(2), 129-138.

Mohd Radzi, et al. (2014). Kepimpinan Transformasional Dan Komitmen Kerja Guru Di Sekolah Rendah SBT Di Negeri Selangor. The 4th Internasional Conference On Learner Diversity, UKM.

Mohd Uzi Dollah. (2015). Perundingan Menulis Tesis dan Disertasi. http://tesisndisertasi.blogspot.com/2015/09/bab-3-kajian-rintis-lahukan-keajian.html $[20$ Jun 2019]. 
Musa, K., Yusof, H., Yunus, J. \& Abdul Hamid, S. (2014). Kepimpinan Transformasional Pengetua: Perbandingan Antara Sekolah Menengah Awam Dan Swasta Cemerlang. Management Research Journal. 3, 120-139.

Noor Azzam Syah Mohamed \& Suria Baba. (2016). Proses Pelaksanaan Pengurusan Kokurikulum Yang Diamalkan Oleh Kumpulan Pengurusan Kokurikulum di Sekolah Menengah Harian. Jurnal kepimpinan Pendidikan, 3(3), 1-27.

Norziana Ayob. (2013). Peranan pengetua dalam pengurusan kokurikulum dari perspektif guru Sekolah Menengah Kebangsaan Zon Keramat. Tesis Sarjana, Fakulti Pendidikan, Universiti Kebangsaan Malaysia.

Nursyafina Saffiee1, Aida Hanim Abdul Hamid2, Ghazali Darusalam. (2018). Amalan Kepimpinan Transformasional dalam Kalangan Guru Besar Terhadap Keberkesanan Sekolah di Daerah Subis. Attarbawiy: Malaysian Online Journal of Education, 2(2), 21-28. http://journal.kuis.edu.my/attarbawiy/wp-content/uploads/2018/12/21-28.pdf [14 Mei 2020]

Nurul Hudani Md. Nawi, Marof Redzuan \& Noor Hisham Md. Nawi. (2013). Pengaruh Aspek Kecerdasan Emosi Terhadap Tingkah Laku Kepimpinan Transformasi dalam Kalangan Pemimpin Pendidik Sekolah. Akademika, 83(2\&3): 3-11.

Norashikin Abu Bakar, Ramli Basri. 2015. Hubungan Kepimpinan Guru dengan Pencapaian Akademik Pelajar. International Journal of Education and Training (InjET). 1-11: 1(2)http://www.injet.upm.edu.my/images/journal/issue2/Hubungan\%20Kepimpinan\%20Guru\%2 0dengan\%20Pencapaian\%20Akademik\%20Pelajar.pdf [3 Jun 2020].

Noornajihan Jaafar \& Ab. Halim Tamuri (2013). Hubungan antara efikasi kendiri dengan kualiti guru pendidikan Islam Sekolah Menengah Kebangsaan Malaysia. JIAE: Journal of Islamic and Arabic Education, 5(1), 41-60.

Ramazan, Mahmut \& Hanifi. (2018). Research on Teacher Self-efficacy in Turkey: 2000-2017. World Journal of Education, 8(4).

Ramli Basri, Norashikin Abu Bakar, dan Foo Say Fooi. (2017). Hubungan Kepimpinan Pengajaran Pengetua dengan Pencapaian Akademik Pelajar. International Research Journal of Education and Sciences (IRJES), 1(1).

Rosmawati binti Abdullah. (2014). Hubungan kepuasan kerja guru di sekolah menengah harian di daerah Seremban, Negeri Sembilan. Seminar Kebangsaan Pengurusan Pendidikan PKPGB 2009 di UTHM.

Rosmawati Abdullah (2013). Kepimpinan Transformasional Pengetua Dan Hubungannya Dengan Kepuasan Kerja Guru SMK Harian Di Daerah Seremban. Tesis Sarjana, Universiti Kebangsaan Malaysia, Bangi Selangor.

Roszanirah Abdul Halim \& Hussein Ahmad. (2015). Kepemimpinan Distributif, Faktor Kontekstual dan Efikasi Kendiri Guru Di Malaysia. Jurnal Kepimpinan Pendidikan.

Ruhaiza Rusmin. (2007). Kepemimpinan Distributif, Faktor Kontekstual dan Efikasi Kendiri Guru Di Malaysia. Jurnal Kepimpinan Pendidikan Kokurikulum Bendung Gejala Sosial.

Sabitha Marican. (2005). "Kaedah Penyelidikan Sains Sosial", Cetakan Pertama, Petaling Jaya, Selangor. Prentice Hall. $91-118$.

Saha, L. J. (2002). Social structure and teacher effects on academic achievement: A comparative analysis. Comparative Education Review, 27(1), 69-98.

Saharuddin Bin Talib. (2017). Aktiviti Kokurikulum Sebagai Pemangkin Kemahiran Kepimpinan Dalam Kalangan Pelajar DRS 2161 (Ragbi). Prosiding Seminar Antarabangsa Kelestarian Insan 2017 (INSAN2017).

Selcuk Demir. (2020). The Role of Self-Efficacy in Job Satisfaction, Organizational Commitment, Motivation and Job Involvement. Eurasian Journal of Educational Research, 85, 205-224.

Siti Awanis, Ainonmadiah \& Siti Noor Ismail. (2016). Tahap Efikasi Guru Dan Hubungannya Dengan Pencapaian Sekolah Di Sekolah-Sekolah Menengah Dalam Daerah Bachok.

Stefan R Ninkovic' \& Olivera C` Kneževic' Floric. (2018). Transformational School Leadership And Teacher Self-Efficacy As Predictors Of Perceived Collective Teacher Efficacy.

Stump, M K. (2017). Trust, Transformational Leadership, and Collective Teacher Efficacy in an Urban School Setting. University of Oklahoma.

Syed Kamaruzaman, Mohd Zaki \& Julismah Jani. (2014). Efikasi Kendiri Guru Pendidikan Jasmani Terhadap Pelaksanaan Pengajaran Mata Pelajaran Pendidikan Jasmani. Jurnal Kurikulum \& Pengajaran Asia Pasifik. 
Tiffany Awkard. (2017). The Power of Reflective Action to Build Teacher Efficacy. 53-57.

Tschannen-Moran, M., \& Hoy, A. W. (2001). Teacher efficacy: Capturing an elusive construct.

Tschannen-Moran, M., Woolfolk Hoy, A., Hoy, W. K. (1998). Teacher efficacy: Its meaning and measure. Review of Educational Research, 68, 202-248.

Unsal, S., Korkmaz, F., \& Percin, S. (2016). Analysis of mathematics teachers' self-efficacy levels concerning the teaching process. Journal of Education and Practice, 7(24), 99-107.

Weiping Jiang, Xianbo Zhao \& Jiongbin Ni. 2017. The Impact of Transformasional Leadership on Employee Sustainable Perfomance: The Mediating Role of Organizational Citizenship Behavior.

Wong Huey Ling (2007). Tahap Penglibatan Pelajar di Sekolah Menengah dalam Aktiviti Kokurikulum dan Hubungannya dengan Pembentukan Daya Kepimpinan. Tesis Sarjana. Universiti Teknologi Malaysia.

Yaakob Daud \& Yahya Don. Budaya Sekolah, Kepemimpinan Transformasional dan Pencapaian Akademik Pelajar. Budaya Sekolah, Kepemimpinan Transformasional: 111-139. http://mjli.uum.edu.my/images/pdf/9mjli/mjli96budaya.pdf [20 Jun 2020].

Zaidatol Akmaliah Lope Piie. (2003). Asas Kepimpinan Transformasional dalam Pendidikan. Pengurusan dan Kepimpinan Pendidikan.UPM Serdang.

Zainal Ariffin Zainuddin, Yaakob Daud \& Saiful Azmi Mohd Nor. (2016). Pengurusan Kokurikulum Dan Tahap Penglibatan Pelajar Dalam Aktiviti Kokurikulum Di Sekolah Menengah Kebangsaan Daerah Kuala Terengganu.

Zulkifli Hassan \& Norazilawati Abdullah. (2016). Penilaian Guru Sekolah Rendah di Daerah Kinta Utara terhadap Pentaksiran Aktiviti Jasmani, Sukan dan Kokurikulum (PAJSK). JPBU Edisi Khas. 